\title{
Respon pertumbuhan vegetatif padi varietas IPB 4S pada kondisi cekaman kekeringan
}

Response of vegetative growth of IPB 4 S varieties in drought stress conditions

\author{
Nasrudin $^{1)^{*}}$, Efrin Firmansyah ${ }^{1)}$ \\ ${ }^{1}$ Program Studi Agroteknologi, Fakultas Pertanian, Universitas Perjuangan Tasikmalaya, Jawa Barat \\ Email korespondensi: nasrudin@unper.ac.id
}

Informasi artikel: Dikirim: 31/05/2020 Ditinjau: $31 / 05 / 2020$ Disetujui: 24/09/2020

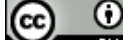

Copyright (c) 2020 Nasrudin, Efrin Firmansyah
ABSTRACT: Drought stress affected growth and decreases rice yield. The use of high yielding varieties and drought tolerance is a strategic step that can be applied during drought stress. The aim of this research was to examine the response of the growth of IPB 4 S rice varieties on planting media with drought stress during vegetative phase. The research used a nonfactorial Completely Randomized Design with six levels: field capacity, 10\% of field capacity, $20 \%$ of field capacity, $30 \%$ of field capacity, $40 \%$ of field capacity, and $50 \%$ of field capacity. The treatments were repeated three times. The growth parameters were plant high, number of tiller, leaf color, leaf area, root length, root dry weight, canopy dry weight, and biomass. The results showed that the drought stress significantly different to leaf area, root length, canopy dry weight, and biomass but were not significantly different to plant height, number of tiller, leaf color, and root dry weight. Increased of drought stress 30 to $50 \%$ of field capacity decreased of leaf area, canopy dry weight, and biomass, but increased root length.

Keywords: ability, factor, farmer,freshwater fish

ABSTRAK: Cekaman kekeringan mempengaruhi pertumbuhan dan menurunkan hasil padi. Penggunaan varietas unggul berproduktivitas tinggi dan toleran kekeringan merupakan langkah strategis yang dapat diterapkan saat terjadinya cekaman kekeringan. Tujuan penelitian yaitu untuk mengkaji respon pertumbuhan padi varietas IPB 4S pada media tanam tercekam kekeringan selama fase vegetatif. Penelitian menggunakan Rancangan Acak Lengkap non-faktorial dengan enam taraf yaitu kapasitas lapang, 10\% kapasitas lapang, 20\% kapasitas lapang, 30\% kapasitas lapang, 40\% kapasitas lapang, dan 50\% kapasitas lapang. Perlakuan diulang sebanyak tiga kali. Parameter yang diamati yaitu tinggi tanaman, jumlah anakan total, warna daun, luas daun, panjang akar, bobot kering akar, bobot kering tajuk, dan biomassa tanaman. Perlakuan cekaman kekeringan berpengaruh nyata terhadap luas daun, panjang akar, bobot kering tajuk, dan biomassa tanaman namun tidak berpengaruh nyata terhadap tinggi tanaman, jumlah anakan total, warna daun, dan bobot kering akar. Peningkatan cekaman kekeringan $30-50 \%$ dari kapasitas lapang menurunkan luas daun, bobot kering tajuk, dan biomassa tanaman namun meningkatkan panjang akar.

Kata kunci: cekaman kekeringan, fase vegetatif, kapasitas lapang, padi, pangan

Sitasi : Nasrudin, N., \& Firmansyah, E. (2020). Respon pertumbuhan vegetatif padi varietas IPB 4 S pada kondisi cekaman kekeringan. AGROMIX, 11(2), 218-226. https://doi.org/10.35891/agx.v11i2.2066

\section{PENDAHULUAN}

Kekeringan merupakan cekaman abiotik dan permasalahan yang sangat serius di dunia yang berkaitan dengan pertanian. Kekeringan menyebabkan pertumbuhan dan produktivitas tanaman menjadi terhambat akibat terbatasnya pasokan air. Keterbatasan air bagi tanaman mengakibatkan proses metabolismenya menjadi terganggu. Hal tersebut karena air memiliki peranan penting terutama 
dalam hal fotosintesis (Lawas dkk., 2018). Berbagai aktivitas manusia yang belakangan ini yang tidak bijak menyebabkan terjadinya pemanasan global dan berakibat pada perubahan iklim. Nasrudin \& Elizani (2019) menyebutkan bahwa perubahan iklim dewasa ini mempengaruhi peningkatan suhu menjadi lebih ekstrim. Perubahan iklim yang terus meningkat akan menjadi penyebab terjadinya kekeringan pada areal pertanaman (Abobatta, 2019). Tasikmalaya misalnya, pada tahun 2019 akibat kemarau panjang sebanyak 252 hektar lahan sawah menjadi kekurangan air (kekeringan) sehingga tidak dapat dimanfaatkan untuk budidaya padi (Putra, 2019).

Kekeringan pada tanaman padi menyebabkan penurunan fase vegetatifnya seperti daun menjadi sempit, laju fotosintesis menurun, jumlah anakan dan biomassa tanaman menurun (Fauza, 2013). Hal tersebut akan menyebabkan penurunan pengisian bulir, kualitas hasil, dan produktivitas (Mostajeran \& Rahimi-Eichi, 2009). Cekaman kekeringan pada padi menyebabkan penurunan produktivitas 10 - 100\% tergantung tingkat cekamannya. Berdasarkan penelitian Nazirah (2017), padi yang ditanam pada kondisi tercekam $20 \%$ dari kapasitas lapang akan menurunkan tinggi tanaman, luas daun, laju asimilasi bersih, kandungan klorofil daun, dan menghambat proses pembungaan.
Berkurangnya lahan produktif yang tidak dapat dimanfaatkan untuk budidaya padi menyebabkan ketersediaan beras di beberapa daerah menjadi terbatas. Seperti diketahui bahwa beras merupakan makanan pokok masyarakat Indonesia yaitu 111,58 kg kapita ${ }^{-1}$ tahun $^{-1}$ (Kementerian Pertanian, 2019). Adapun jumlah penduduk Indonesia sebesar 269 juta jiwa dengan laju pertumbuhan penduduk sebesar 1,19\% (BPS, 2013). Apabila produksi padi tidak stabil maka jumlah penduduk dengan stok beras yang tersedia tidak berimbang. Hal tersebut menyebabkan kekurangan bahan pangan pada sejumlah masyarakat. Oleh sebab itu, perlu usaha yang dilakukan agar produksi padi tetap dapat ditingkatkan meskipun dalam kondisi tercekam kekeringan. Upaya tersebut selain untuk mencukupi kebutuhan pangan masyarakat juga agar tercipta kedaulatan pangan di Indonesia.

Salah satu strategi yang dapat dilakukan yaitu dengan menanam varietas toleran kekeringan dengan produktivitas yang tinggi. Padi varietas IPB 4S memiliki keunggulan yaitu potensi hasilnya mencapai 10 ton.ha ${ }^{-1}$. Apabila padi varietas IPB 4 S ini dapat ditanam dan mampu berproduksi secara optimal pada kondisi kekeringan maka akan menguntungkan bagi petani dan menjadi strategi yang sangat baik dalam produksi padi. Oleh sebab itu, perlu dilakukan uji terhadap padi varietas IPB 4S yang ditanam pada media tanam tercekam kekeringan dengan tingkatan yang berbeda. 
Diharapkan hasil penelitian ini dapat menjadi langkah awal untuk menentukan varietas terbaik yang dapat ditanam pada kondisi kekeringan. Tujuan penelitian yaitu untuk mengkaji respon pertumbuhan padi varietas IPB 4S pada media tanam tercekam kekeringan selama fase vegetatif.

\section{METODE}

\section{Alat dan bahan}

Alat-alat yang digunakan antara lain: polybag ukuran $30 \times 40 \mathrm{~cm}$, selang, meteran, bagan warna daun, oven, timbangan digital, timbangan digital dengan tingkat akurasi 0,01, alat tulis, cangkul, sabit, gembor, gelas ukur, kamera, karton asturo warna hitam, milimeter blok, dan amplop cokelat untuk sampel. Bahanbahan yang digunakan antara lain: benih padi varietas IPB 4S, tanah, pupuk NPK 16:16:16, dan sekam padi.

\section{Tempat penelitian}

Penelitian dilaksanakan pada bulan Januari - April 2020 di Rumah Plastik Fakultas Pertanian Universitas Perjuangan Tasikmalaya dengan ketinggian tempat 359 mdpl.

\section{Rancangan percobaan}

Penelitian menggunakan Rancangan Acak Lengkap (RAL) non-faktorial dengan enam taraf yaitu: K0 (kapasitas lapang); K1 (10\% kapasitas lapang); K2 (20\% kapasitas lapang); K3 (30\% kapasitas lapang); K4 (40\% kapasitas lapang); dan K5 (50\% kapasitas lapang). Percobaan terdiri atas 6 perlakuan dan diulang sebanyak tiga kali sehingga terdapat 18 unit percobaan. Perlakuan cekaman kekeringan dilakukan dengan cara memberikan air pada masingmasing media tanam dan dibiarkan sampai kapasitas lapang. Setelah kondisi kapasitas lapang tercapai kemudian ditimbang dan masing-masing media tanam dibiarkan berada pada kondisi kekeringan sampai tingkatan tertentu sesuai dengan perlakuan yaitu $10 \%$, $20 \%$, 30\%, $40 \%$, dan $50 \%$. Media tanam dalam kapasitas lapang memiliki bobot $5 \mathrm{~kg}$, maka saat tercekam kekeringan $10 \%$ media tanam berbobot sebesar $4,5 \mathrm{~kg}$, saat tercekam kekeringan 20\% media tanam berbobot $4 \mathrm{~kg}$, saat tanaman tercekam kekeringan 30\% media tanam berbobot 3,5 kg, saat tanaman tercekam kekeringan $40 \%$ media tanam berbobot $3 \mathrm{~kg}$, dan saat tanaman tercekam kekeringan 50\% media tanam berbobot $2,5 \mathrm{~kg}$. Adapun perlakuan atau kondisi cekaman kekeringan pada media tanam diamati setiap dua minggu sekali. Metode tersebut dilakukan untuk menjaga kondisi media tanam agar tetap sesuai dengan perlakuan yang diberikan.

Parameter yang diamati antara lain: tinggi tanaman $(\mathrm{cm})$ yang diukur menggunakan meteran yang dilakukan dari pangkal batang sampai ujung daun tertinggi. Jumlah anakan total dihitung pada setiap kali pengamatan jumlah anakan yang tumbuh dan dilakukan secara manual. Warna daun diamati menggunakan alat bagan warna daun yang dilakukan dengan cara menyamakan warna 
daun dengan warna yang terdapat pada alat tersebut. Pengamatan tinggi tanaman, jumlah anakan total, dan warna daun dilakukan setiap dua minggu sekali dimulai pada minggu kedua setelah pindah tanam. Luas daun $\left(\mathrm{cm}^{2}\right)$, panjang akar $(\mathrm{cm})$, bobot kering akar $(\mathrm{g})$, bobot kering tajuk (g), dan biomassa tanaman (g) dilakukan pengamatan secara destruktif. Luas daun diukur dengan cara menggambar daun padi yang diamati pada kertas milimeter blok kemudian dihitung luasan pada daun yang tergambar. Panjang akar diukur menggunakan meteran dari pangkal akar sampai ujung akar terpanjang. Tajuk, akar, dan biomassa tanaman dilakukan dengan cara mengeringkan masingmasing bagian tanaman (tajuk dan akar) menggunakan oven pada suhu $80{ }^{\circ} \mathrm{C}$ selama 24 jam. Setelah kering kemudian ditimbang menggunakan timbangan digital dengan akurasi 0,01 g. Pengamatan luas daun, panjang akar, bobot kering akar, bobot kering tajuk, dan biomassa tanaman diamati sebanyak dua kali yaitu saat tanaman berumur 4 mst (fase vegetatif awal) dan 8 mst (fase vegetatif maksimum).

\section{Analisis data}

Data kuantitatif yang diperoleh melalui pengamatan kemudian dianalisis menggunakan analisis ragam (ANOVA). Apabila terdapat perbedaan di antara perlakuan, maka dilanjutkan dengan Uji DMRT (Duncan's multiple range test) pada taraf kesalahan 5\%. Pengolahan analisis data statistik menggunakan software Statistical Tool for Agricultural Research (STAR) ver 2.0.1.

\section{HASIL DAN PEMBAHASAN}

Padi merupakan salah satu tanaman yang masa pertumbuhannya akan sangat menentukan produktivitas. Pertumbuhan yang optimal pada padi akan menghasilkan asimilat yang cukup untuk pembentukan bulir padi. Pertumbuhan padi yang optimal didukung oleh kondisi lingkungan yang baik seperti ketersediaan air yang merupakan salah satu faktor penting dalam pertumbuhan dan perkembangan tanaman. Keterbatasan air akan sangat mempengaruhi pertumbuhan padi sehingga kualitas hasil dan produktivitasnya akan menurun.

Tabel 1 menunjukkan bahwa padi varietas IPB 4S yang ditanam pada kondisi media tanam tercekam kekeringan tidak menunjukkan perbedaan pertumbuhan tinggi tanaman dan jumlah anakan pada masing-masing perlakuan setiap pengamatan. Meskipun demikian, pertumbuhan padi varietas IPB 4S pada masingmasing perlakuan mengalami peningkatan tinggi tanaman. Gambar 1 menunjukkan bahwa perlakuan kapasitas lapang sampai 10\% dari kapasitas lapang mempengaruhi pertumbuhan tinggi tanaman yang lebih baik. Ketika cekaman kekeringan ditingkatkan $20-50 \%$ tinggi tanaman pada setiap pengamatan cenderung stabil dan tidak lebih baik dibandingkan pada kondisi kapasitas lapang sampai 10\% kapasitas 
lapang. Hal tersebut diduga karena saat kekurangan air dapat menyebabkan tanaman memasuki fase vegetatif tanaman padi padi lambat dalam laju fotosintesis, membutuhkan banyak air untuk mendukung menurunnya turgiditas sel mempengaruhi pertumbuhan dan perkembangannya. tutup buka stomata serta proses transpirasi Supriyanto (2013) menyebutkan bahwa tanaman.

Tabel 1. Tinggi tanaman $(\mathrm{cm})$ dan jumlah anakan total padi varietas IPB 4 S yang ditanam pada media tanam tercekam kekeringan selama fase vegetatif

\begin{tabular}{lcccccccc}
\hline & \multicolumn{3}{c}{ Tinggi tanaman $(\mathbf{c m})$} & \multicolumn{4}{c}{ Jumlah anakan total } \\
\cline { 2 - 9 } Perlakuan & $\mathbf{2}$ & $\mathbf{4}$ & $\mathbf{6}$ & $\mathbf{8}$ & $\mathbf{2}$ & $\mathbf{4}$ & $\mathbf{6}$ & $\mathbf{8}$ \\
& mst & mst & mst & mst & mst & mst & mst & mst \\
\hline K0 (kapasitas lapang) & 36,35 & 57,90 & 72,30 & 78,87 & 3,2 & 6,3 & 10 & 10,3 \\
K1 (10\% kapasitas lapang) & 38,52 & 55,50 & 69,30 & 76,50 & 4,5 & 8,3 & 8,3 & 9,3 \\
K2 (20\% kapasitas lapang) & 36,08 & 49,47 & 60,33 & 70,37 & 4,3 & 7,0 & 9,7 & 10,3 \\
K3 (30\% kapasitas lapang & 36,50 & 50,27 & 56,53 & 76,67 & 3,8 & 5,3 & 7,7 & 8,7 \\
K4 (40\% kapasitas lapang) & 38,22 & 51,77 & 58,37 & 70,53 & 3,8 & 6,0 & 8,7 & 9,7 \\
K5 (50\% kapasitas lapang) & 38,40 & 52,67 & 55,50 & 68,50 & 4,8 & 6,0 & 6,7 & 7,7 \\
\hline CV (\%) & $\mathbf{5 , 9}$ & $\mathbf{7 , 1}$ & $\mathbf{1 1 , 9}$ & $\mathbf{1 0 , 5}$ & $\mathbf{2 5 , 3}$ & $\mathbf{2 3 , 5}$ & $\mathbf{2 6 , 7}$ & $\mathbf{2 0 , 3}$ \\
\hline
\end{tabular}

Keterangan: mst (minggu setelah tanam); angka yang diikuti oleh huruf yang berbeda pada kolom yang sama, tidak beda nyata pada uji jarak berganda duncan dengan taraf kesalahan $5 \%$.

\begin{tabular}{|c|c|c|c|c|}
\hline 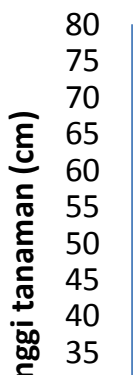 & & wakt & & \\
\hline+50 & 2 & 4 & 6 & 8 \\
\hline$\rightarrow \mathrm{KO}$ & 36.35 & 57.9 & 72.3 & 78.87 \\
\hline$\longrightarrow \mathrm{K} 1$ & 38.52 & 55.5 & 69.3 & 76.5 \\
\hline$-\mathrm{K} 2$ & 36.08 & 49.47 & 60.33 & 70.37 \\
\hline$\multimap \mathrm{K} 3$ & 36.5 & 50.37 & 56.53 & 76.67 \\
\hline$-\mathrm{K} 4$ & 38.22 & 51.77 & 58.37 & 70.53 \\
\hline$\longrightarrow \mathrm{K} 5$ & 38.4 & 52.67 & 55.5 & 68.5 \\
\hline
\end{tabular}

Gambar 1. Pertumbuhan tinggi tanaman padi varietas IPB 4S saat 2 - 8 mst.

Tabel 1 juga menunjukkan bahwa lapang memberikan kondisi lingkungan yang perlakuan cekaman kekeringan pada padi kurang sesuai untuk pertumbuhan padi varietas varietas IPB 4S tidak berpengaruh nyata IPB 4S sehingga memiliki jumlah anakan yang terhadap jumlah anakan. Diduga pada fase relatif sama. Meskipun demikian perlakuan kapasitas lapang sampai $50 \%$ dari kapasitas cekaman kekeringan 50\% kapasitas lapang 
memberikan jumlah anakan yang paling sedikit. terhambat sehingga pertumbuhan anakannya Selama padi mengalami keterbatasan pasokan pun akan menurun (Adnyana dkk., 2013; Lipiec air, maka perkembangan selnya akan dkk., 2013; Setiani, 2016).

Tabel 2. Warna daun dan luas daun $\left(\mathrm{cm}^{2}\right)$ padi varietas IPB 4 S yang ditanam pada media tanam tercekam kekeringan selama fase vegetatif

\begin{tabular}{|c|c|c|c|c|c|c|}
\hline \multirow{2}{*}{ Perlakuan } & \multicolumn{4}{|c|}{ Warna daun } & \multicolumn{2}{|c|}{ Luas daun $\left(\mathrm{cm}^{2}\right)$} \\
\hline & $2 \mathrm{mst}$ & $4 \mathrm{mst}$ & $6 \mathrm{mst}$ & $8 \mathrm{mst}$ & $4 \mathrm{mst}$ & 8 mst \\
\hline K0 (kapasitas lapang) & 3,33 & 3,00 & 3,33 & 4,00 & 222,60 & $780,37^{b}$ \\
\hline K1 (10\% kapasitas lapang) & 3,00 & 3,33 & 2,67 & 4,00 & 350,23 & $1103,85^{\circ}$ \\
\hline K2 (20\% kapasitas lapang) & 3,17 & 3,33 & 2,67 & 3,33 & 231,09 & $781,20^{b}$ \\
\hline K3 (30\% kapasitas lapang & 3,00 & 3,33 & 2,33 & 4,00 & 194,35 & $480,37^{c}$ \\
\hline K4 (40\% kapasitas lapang) & 3,50 & 3,67 & 3,33 & 3,67 & 419,42 & $605,53^{b c}$ \\
\hline K5 (50\% kapasitas lapang) & 3,33 & 3,67 & 3,00 & 3,67 & 285,71 & $362,43^{c}$ \\
\hline CV (\%) & 19,00 & 15,55 & 23,08 & 10,81 & 25,91* & 19,44 \\
\hline
\end{tabular}

Keterangan: mst (minggu setelah tanam); * (data ditransformasi); angka yang diikuti oleh huruf yang berbeda pada kolom yang sama, tidak beda nyata pada uji jarak berganda duncan dengan taraf kesalahan $5 \%$.

Tabel 2 menunjukkan bahwa perlakuan cekaman kekeringan tidak berpengaruh nyata terhadap warna daun. Hal tersebut diduga meskipun media tanam memiliki keterbatasan air, namun tanaman masih tercukupi kebutuhan haranya terutama nitrogen yang diberikan melalui aplikasi pemupukan NPK. Tanaman padi akan menginvestasikan sebagian besar awal pertumbuhannya untuk penambahan luas daun (Gardner dkk., 1991). Tabel 2 menunjukkan bahwa luas daun saat tanaman berumur 4 mst tidak berpengaruh nyata terhadap perlakuan cekaman kekeringan. Peningkatan cekaman kekeringan 30 - 50\% cekaman kekeringan saat padi berumur $8 \mathrm{mst}$ mampu mempersempit daun. Kumar dkk. (2019) menyebutkan bahwa saat tanaman kekurangan air, maka laju fotosintesisnya akan menurun sehingga menyebabkan asimilat yang dihasilkan untuk pertambahan luas daun pada fase vegetatif menjadi terhambat. Oleh sebab itu, peningkatan cekaman kekeringan $30-50 \%$ menghambat penambahan luas daun (daun padi menjadi lebih sempit). Penurunan laju fotosintesis tanaman merupakan respon awal tanaman terhadap kondisi defisit air yaitu menutupnya stomata (Juairiah, 2014). Meskipun demikian, saat tercekam kekeringan secara fisiologis tanaman memiliki mekanisme ketahanan dengan cara mengurangi laju transpirasi yang ditandai dengan menutupnya stomata namun laju fotosintesis akan ditingkatkan dengan cara meningkatkan kandungan klorofil (Hidayati dkk., 2017).

Akar merupakan salah satu organ penting pada tanaman untuk memasok air, hara, dan bahan lainnya pada tanaman. Selama fase vegetatif, pertumbuhan akar merupakan salah satu organ yang terus berkembang selain daun. Tabel 3 menunjukkan bahwa akar padi varietas 
IPB yang ditanam pada kondisi tercekam kekeringan 50\% kapasitas lapang lebih panjang dibandingkan padi yang ditanam pada perlakuan lainnya. Pemanjangan akar padi diduga merupakan usaha tanaman dalam mencari air dan hara untuk mendukung pertumbuhan dan perkembangannya. Padi memiliki kemampuan untuk menerobos ke dalam tanah untuk memanjangkan akarnya saat terjadi cekaman kekeringan (Maisura dkk
2017). Swapna dan Shylaraj

(2017) menyebutkan bahwa pemanjangan akar padi saat tercekam kekeringan merupakan suatu mekanisme ketahanan tanaman drought avoidance dalam beradaptasi pada lingkungan. Meskipun memiliki perbedaan panjang akar pada masing-masing perlakuan cekaman kekeringan, namun bobot kering akar tidak berbeda nyata terhadap perlakuan cekaman kekeringan yang diberikan.

Tabel 3. Panjang akar $(\mathrm{cm})$ dan bobot kering akar $(\mathrm{g})$ padi varietas IPB 4 S yang ditanam pada media tanam tercekam kekeringan selama fase vegetatif

\begin{tabular}{|c|c|c|c|c|}
\hline \multirow{2}{*}{ Perlakuan } & \multicolumn{2}{|c|}{ Panjang akar (cm) } & \multicolumn{2}{|c|}{ Bobot kering akar (g) } \\
\hline & $4 \mathrm{mst}$ & $8 \mathrm{mst}$ & $4 \mathrm{mst}$ & $8 \mathrm{mst}$ \\
\hline KO (kapasitas lapang) & $5,50^{b}$ & 15,30 & 0,067 & 0,713 \\
\hline K1 (10\% kapasitas lapang) & $8,43^{\mathrm{ab}}$ & 18,73 & 0,103 & 0,793 \\
\hline K2 (20\% kapasitas lapang) & $7,47^{b}$ & 20,47 & 0,127 & 0,507 \\
\hline K3 (30\% kapasitas lapang & $8,47^{\mathrm{ab}}$ & 21,07 & 0,103 & 0,567 \\
\hline K4 (40\% kapasitas lapang) & $9,57^{\mathrm{ab}}$ & 8,27 & 0,040 & 0,300 \\
\hline K5 (50\% kapasitas lapang) & $11,13^{\mathrm{a}}$ & 15,53 & 0,197 & 0,740 \\
\hline CV (\%) & 21,57 & $25,69 *$ & $5,64^{*}$ & $11,81^{*}$ \\
\hline
\end{tabular}

Keterangan: mst (minggu setelah tanam); ${ }^{*}$ (data ditransformasi); angka yang diikuti oleh huruf yang berbeda pada kolom yang sama, tidak beda nyata pada Uji Jarak Berganda Duncan dengan taraf kesalahan $5 \%$.

Tabel 4. Bobot kering tajuk (g) dan biomassa tanaman (g) padi varietas IPB 4S yang ditanam pada media tanam tercekam kekeringan selama fase vegetatif

\begin{tabular}{lcccc}
\hline \multirow{2}{*}{ Perlakuan } & \multicolumn{2}{c}{ Bobot kering tajuk (g) } & \multicolumn{2}{c}{ Biomassa tanaman (g) } \\
\cline { 2 - 5 } & $\mathbf{4}$ $\mathbf{~ s t}$ & $\mathbf{8} \mathbf{~ m s t}$ & $\mathbf{4}$ $\mathbf{s t}$ & $\mathbf{8}$ $\mathbf{s t}$ \\
\hline K0 (kapasitas lapang) & 0,48 & $3,14^{\mathrm{a}}$ & 0,55 & $3,86^{\mathrm{a}}$ \\
K1 (10\% kapasitas lapang) & 0,76 & $2,93^{\mathrm{a}}$ & 0,86 & $3,72^{\mathrm{a}}$ \\
K2 (20\% kapasitas lapang) & 0,76 & $1,27^{\mathrm{b}}$ & 0,89 & $1,78^{\mathrm{b}}$ \\
K3 (30\% kapasitas lapang & 0,70 & $1,48^{\mathrm{b}}$ & 0,81 & $2,05^{\mathrm{b}}$ \\
K4 (40\% kapasitas lapang) & 0,71 & $1,64^{\mathrm{b}}$ & 0,75 & $1,94^{\mathrm{b}}$ \\
K5 (50\% kapasitas lapang) & 0,76 & $1,68^{\mathrm{b}}$ & 0,96 & $2,42^{\mathrm{b}}$ \\
\hline CV (\%) & $\mathbf{1 2 , 4 5 ^ { * }}$ & $\mathbf{1 4 , 4 2}$ & $\mathbf{1 2 , 3 9 *}$ & $\mathbf{1 8 , 4 0}$
\end{tabular}

Keterangan: mst (minggu setelah tanam); ${ }^{*}$ (data ditransformasi); angka yang diikuti oleh huruf yang berbeda pada kolom yang sama, tidak beda nyata pada Uji Jarak Berganda Duncan dengan taraf kesalahan $5 \%$.

Keterbatasan air menurunkan bobot ditanam pada kapasitas lapang dan $10 \%$ kering tajuk dan biomassa tanaman. Tabel 4 kapasitas lapang memiliki bobot kering tajuk menunjukkan bahwa padi varietas IPB 4S yang dan biomassa lebih tinggi dibandingkan 
perlakuan lainnya. Hal tersebut diduga semakin tinggi cekaman kekeringan akan membatasi tanaman dalam melakukan proses fotosintesis. Luas daun berhubungan terhadap bobot kering tajuk dan biomassa tanaman. Daun yang menyempit saat tercekam kekeringan mempengaruhi penurunan laju transpirasi, laju fotosintesis, dan produksi biomassa tanaman (Yang dkk., 2019).

Pertumbuhan vegetatif pada padi sangat menentukan keberhasilan produktivitasnya. Misalnya luas daun sangat mempengaruhi produksi biomassa yang dihasilkan dari terbentuknya asimilat melalui proses fotosintesis. Asimilat yang dihasilkan digunakan untuk pertumbuhan organ tanaman serta saat memasuki fase generatif berperan untuk pengisian gabah. Oleh sebab itu penting mengetahui ketahanan suatu varietas padi terhadap cekaman kekeringan untuk menentukan varietas yang akan ditanami.

\section{KESIMPULAN}

Padi varietas IPB 4 S yang ditanam pada media tanam tercekam kekeringan memiliki respon pertumbuhan selama fase vegetatif yang berbeda-beda pada setiap perlakuan. Peningkatan cekaman kekeringan 30 - 50\% dari kapasitas lapang menurunkan luasan daun, bobot kering tajuk, dan biomassa namun memperpanjang akar tanaman. Meskipun demikian, perlakuan cekaman kekeringan pada padi IPB 4S tidak mempengaruhi perbedaan yang nyata pada parameter tinggi tanaman, jumlah anakan, warna daun, dan bobot kering akar. Berdasarkan hasil yang didapat padi varietas IPB 4S juga memiliki toleransi terhadap cekaman kekeringan hingga 10\% dari kapasitas lapang yang ditunjukkan pada parameter tinggi tanaman, jumlah anakan, warna daun, dan luas daun saat tanaman berumur 4 mst.

\section{DAFTAR PUSTAKA}

Abobatta, W. F. (2019). Drought adaptive mechanisms of plants - a review. Advances in Agriculture and Environmental Science, 2(1), 61-65. https://doi.org/10.30881/aaeoa.00021

Adnyana, G. M., Sukewijaya, I. M., \& Mayadewi, N. Y. A. (2013). Mekanisme adaptasi tanaman padi pada kondisi cekaman kekeringan dan upaya mengatasi kegagalan panen (review). AGROTROP, 3(1), 11-16.

BPS. (2013). Proyeksi penduduk Indonesia 20202035. Badan Pusat Statistik. https://bps.go.id

Fauza, Y. (2013). Pengaruh cekaman kekeringan terhadap pertumbuhan dan produksi galur-galur padi (Oryza sativa L.) sawah [Thesis, Institut Pertanian Bogor]. https://www.repository.ipb.ac.id

Gardner, F. P., Pearce, R. B., \& Mitchell, R. L. (1991). Fisiologi tanaman budidaya. Jakarta: UI Press.

Hidayati, N., Hendrati, R. L., Triani, A., \& Sudjino. (2017). Pengaruh kekeringan terhadap pertumbuhan dan perkembangan tanaman nyamplung (Callophylum inoplyllum L.) dan Johar (Cassia florida Vahl.) dari provenan yang berbeda. Jurnal Pemuliaan Tanam Hutan, 11(2), 99-111.

Juairiah, L. (2014). Studi karakteristik stomata beberapa jenis tanaman revegetasi di lahan pascapenambangan timah di Bangka. Widyariset, 17(2), 213-218. 
http://dx.doi.org/10.14203/widyariset.17 .2.2014.213-217

Kementerian Pertanian. (2019). Stok beras aman sampai 2020. Kementerian Pertanian. https://www.pertanian.go.id/ home/?show=news\&act=view\&id $=4108$

Kumar, A., Nayak, A. K., Das, B. S., Panigrahi, N., Dasgupta, P., Mohanty, S., Kumar, U., Panneerselvam, P., \& Pathak, H. (2019). Effects of water deficit stress on agronomic and physiological responses of rice and greenhouse gas emission from rice soil under elevated atmospheric $\mathrm{CO}_{2}$. Science of the Total Environment, 650(2019), 2032-2050. https://doi.org/ 10.1016/j.scitotenv.2018.09.332

Lawas, L. M. F., Shi, W., Yoshimoto, M., Hasegawa, T., Hincha, D. K., Zuther, E., \& Jagadish, S. V. K. (2018). Combined drought and heat stress impact during flowering and grain filling in contrasting rice cultivars grown under field conditions. Field Crop Research, 229(2018), 66-77. https://doi.org/10. 1016/j.fcr.2018.09.009

Lipiec, J., Doussan, C., Nosalewicz, A., \& Kondracka, K. (2013). Effect of drought and heat stresses on plant growth and yield: a review. International Agrophysics, 27(4), 463-477.

Maisura., Chozin, M. A., Lubis, I., Junaedi, A., \& Ehara, H. (2017). Studi karakter morfologi dan fisiologi varietas padi toleran terhadap cekaman kekeringan pada sistem sawah. Jurnal Agrium, 14(1), 8-16. https://doi.org/10.29103/agrium.v14i1.8 69

Mostajeran, A., \& Rahimi-Eichi, V. (2009). Effects of drought stress on growth and yield of rice (Oryza sativa L.) cultivars and accumulation of proline and soluble sugars in sheath and blades of their different ages leaves. American-Eurasian Journal of Agriculture \& Environment Science, 5(2), 264-272.

Nasrudin, \& Elizani, P. (2019). Kajian dampak La Nina terhadap kualitas hasil salak pondoh (Sallacca edulis Reinw.) selama penyimpanan suhu ruang. Jurnal Galung
Tropika, 8(2), 103-111. http://dx.doi.org/ 10.31850/jgt.v8i2.438

Nazirah, L. (2017). Karakter morfofisiologi padi gogo toleran cekaman kekeringan pada olah tanah konservasi dan pemberian mikoriza [disertasi, Universitas Sumatera Utara]. http://repositori.usu.ac.id/handle $/ 123456789 / 2872$

Putra, N. N. (2019). 252 hektare lahan pertanian di Kota Tasikmalaya terdampak kekeringan. media RRI. http:// www.m.rri.co.id/post/berita/700663/dae rah/252_hektare_lahan_pertanian_di_ko ta_tasikmalaya_terdampak_kekeringan.h tml

Setiani, S. (2016). Penggunaan input dalam produksi padi oleh rumah tangga petani di daerah agroekosistem lahan sawah dan kering. Agromix, 7(2), 42-56. https://doi.org/10.35891/agx.v7i2.710

Supriyanto, B. (2013). Pengaruh cekaman kekeringan terhadap pertumbuhan dan hasil padi gogo lokal kultivar jambu (Oryza sativa Linn.). Jurnal AGRIFOR, 12(1), 77-82. https://doi.org/10.31293/ af.v12i1.182

Swapna, S. S., \& Shylaraj, K. S. (2017). Screening for osmotic stress responses in rice varieties under drought condition. Rice science, 24(5), 253-263. https://doi.org/ 10.1016/j.rsci.2017.04.004

Yang, X., Wang, B., Chen, L., Li, P., \& Cao, C. (2019). The different influences of drought stress at the flowering stage on rice physiological traits, grain yield, and quality. Scientific reports, 9(1), 1-12. https://doi.org/10.1038/s41598-01940161-0 